\title{
Evolution of the Asian-African Monsoonal Precipitation over the last 21 kyr and the Associated Dynamic Mechanisms ${ }^{\mathfrak{O}}$
}

\author{
JIAN SHI \\ Collaborative Innovation Center on Forecast and Evaluation of Meteorological Disasters, and Key Laboratory \\ of Meteorological Disaster, Ministry of Education, Nanjing University of Information Science and Technology, \\ Nanjing, China \\ QING YAN \\ Nansen-Zhu International Research Centre, Institute of Atmospheric Physics, and CAS Center for Excellence in \\ Tibetan Plateau Earth Sciences, Chinese Academy of Sciences, Beijing, China
}

(Manuscript received 28 January 2019, in final form 29 May 2019)

\begin{abstract}
The Asian-African monsoonal precipitation (AAMP) has a significant impact on the water availability, biodiversity, and livelihoods of billions of people. A comprehensive understanding of the AAMP behavior over Earth's history will help to make better future projections. Using a set of transient climate simulations over the last 21000 years $(21 \mathrm{ka})$, the variation of the AAMP and its responses to various external forcings, including orbital insolation, greenhouse gases (GHGs), and ice sheets, are explored. The precipitation evolutions in the individual monsoon domains have the characteristic of hemispheric synchrony over the last 21 ka. Specifically, the AAMP increased from the Last Glacial Maximum to the early Holocene with several abrupt events and then decreased subsequently. The raised orbital insolation and GHGs lead to an overall AAMP increase, but the enhanced insolation tends to induce a systematic northward shift of the AsianAfrican monsoon domain. Decreased meltwater discharge could promote the African and Indian monsoonal precipitation through strengthening the Atlantic Ocean meridional overturning circulation. However, the lowering of ice sheets (i.e., orographic effect) results in an anomalous dipole precipitation pattern between North China and India. An analysis of the moisture budget suggests that, although different external forcings may lead to the same sign of precipitation change (e.g., both increased insolation and GHGs can cause the enhanced AAMP), the thermodynamic and dynamic contributions to precipitation could vary greatly by region and forcing. This study provides a reference for the long-term behavior of the AAMP with rising GHGs, higher insolation, and potential melting of the Greenland Ice Sheet.
\end{abstract}

\section{Introduction}

The Asian-African monsoon, including the East Asian, Indian, and North African monsoons, is the dominant system over the Northern Hemisphere and controls the hydrologic cycle over the three regions. Precipitation over the Asian-African monsoon domain is concentrated in summer and results from the moisture transported from adjacent oceans, which affects the water availability, biodiversity, and the livelihoods of billions of people across

\footnotetext{
Supplemental information related to this paper is available at the Journals Online website: https://doi.org/10.1175/JCLI-D-190074.s1.

Corresponding author: Qing Yan, yanqing@mail.iap.ac.cn
}

Africa and Asia. Therefore, questions about how the Asian-African monsoonal precipitation (AAMP) may vary with the changing climate have been investigated. Previous studies show that the interannual and interdecadal time scale changes of the AAMP are largely attributed to the combined effects of natural forcings, such as solar activity and volcanic eruptions (Tan et al. 2009; Anchukaitis et al. 2010; Man et al. 2014) and anthropogenic factors such as greenhouse gases (GHGs) and aerosols (Lau et al. 2006; Ashfaq et al. 2009; Bollasina et al. 2011).

Climate models project an increased AAMP in the twenty-first century as a result of increased GHG levels according to the Intergovernmental Panel on Climate Change (IPCC) Fifth Assessment Report (IPCC 2013). However, several potential forcings are not considered 
in the current long-term projections, especially at the millennial time scale. In a foreseeable warmer world, the rising GHG concentrations could induce a complete melting of the Greenland Ice Sheet, changing its topography and increasing the meltwater discharge (Greve 2000; Huybrechts et al. 2011; Yan et al. 2014). Furthermore, the combined effect of the varying orbital parameters will continuously increase the summer insolation over the Northern Hemisphere in the future (Berger 1978). Thus, we should take these factors into consideration and perform a more comprehensive investigation of the corresponding AAMP changes for better future projections.

Exploring climate variations over Earth's history, during which ice sheets, orbital insolation, and carbon dioxide $\left(\mathrm{CO}_{2}\right)$ concentrations have undergone significant changes, can increase our knowledge of the AAMP's response to various external forcings. The Last Glacial Maximum [LGM; 21000 years ago (hereinafter $21 \mathrm{ka}$ )] was the last period during which extent of the Northern Hemisphere ice sheets was at a maximum, and it also featured different orbital parameters and lower GHG concentrations. Since then, the Northern Hemisphere ice sheets have gradually retreated and reached their present level at $\sim 6 \mathrm{ka}$ before present (BP) (Peltier 2004). The orbital parameters (i.e., precession and axial tilt) have varied precisely following the astronomical calculations (Berger 1978), with Northern Hemisphere summer insolation increasing from 21 to $11 \mathrm{ka} \mathrm{BP}$ and subsequently decreasing. GHG concentrations continually increased during the transition from the LGM to the present (Clark et al. 2009). Therefore, the last $21 \mathrm{ka}$ (from the LGM to the present) opens a golden avenue to study the responses of the AAMP to more varied external forcings than the present day.

Geological evidence shows that the AAMP has exhibited remarkable changes since the LGM. Based on speleothem records, Wang et al. (2008) found that the East Asian monsoon precipitation was increased from the LGM to the early Holocene and then decreased to the present, which is confirmed by proxies from other Chinese speleothem records (Yuan et al. 2004; Dykoski et al. 2005). The Indian (Wang et al. 2010; Govil and Naidu 2011; Gebregiorgis et al. 2016) and tropical North African (Gasse and Van Campo 1994; Gasse 2000; Revel et al. 2014; Armitage et al. 2015) monsoonal precipitation records show similar trend evolutions, but the timing of the peak precipitation appears to be different from the East Asian monsoon records. These records demonstrate the crucial role of precession-induced insolation changes on the AAMP. However, Lu et al. (2013) revealed that the
East Asian monsoon precipitation (based on loess records) has increased rapidly since the early Holocene, emphasizing the effect of GHGs rather than orbital insolation. These proxies help place the behavior of the modern AAMP in a long-term paleoclimatic context but provide limited information about the associated dynamic mechanisms.

Numerical simulations are widely used to explore the causes of regional and global monsoon evolution in the past. Many equilibrium simulations have been performed to test the responses of the AAMP, as well as other aspects of climate, to external forcings, such as the LGM and mid-Holocene experiments from the Paleoclimate Modeling Intercomparison Project (PMIP) (Weber et al. 2007; Ramstein et al. 2007; Pinot et al. 1999). For example, the PMIP simulations showed that global monsoonal precipitation was weakened during the LGM but increased during the mid-Holocene relative to the present (Jiang et al. 2015a,b; Yan et al. 2016). In recent years, transient simulations have become a more powerful tool in paleoclimate research; they can reveal the continuous change of the climate and be used for detailed model-data comparisons, thus providing more information about the climate response than equilibrium simulations. Wen et al. (2016) investigated the evolution of the East Asian monsoon since the LGM and found that the summer monsoon was positively and negatively correlated with the winter monsoon on orbital and millennial time scales, respectively. Zhang and Jin (2016) further indicated that the circumglobal teleconnection is the bridge linking the Asian summer monsoon to orbital insolation. In addition to orbital forcing, $\mathrm{Lu}$ et al. (2019) noted that high-latitude forcing (i.e., ice volume) and low-latitude forcing (i.e., tropical sea surface) exert great influences on the East Asian summer monsoon. For the North African monsoonal precipitation, four transient simulations consistently indicated a nearly linear response to insolation change since the mid-Holocene (Dallmeyer et al. 2015). Shanahan et al. (2015) compared the reconstruction and simulations of the African monsoon evolution since the LGM and concluded that the synchronous (asynchronous) precipitation changes are caused by variations in the monsoon intensity (position).

Previous studies improved our knowledge on the variations of individual monsoon systems in the Northern Hemisphere, but few of them pay attention to the evolution of hemispheric monsoons. Actually, individual monsoon systems are dynamically interconnected through velocity potential maintenance and mass conservation (Chen 2003; Trenberth et al. 2000). From the perspective of global monsoon, the variations of hemispheric-scale monsoons largely result from the 
TABLE 1. The TraCE-21ka full-forcing experiment and four sensitive experiments. An em dash indicates that the forcing is fixed at the beginning of the corresponding experiment.

\begin{tabular}{|c|c|c|c|c|c|}
\hline & Orbital & GHGs & Meltwater & Ice sheets & Time span \\
\hline TraCE-full & Transient & Transient & Transient & Transient & $22-0 \mathrm{ka} \mathrm{BP}$ \\
\hline TraCE-ORB & Transient & - & - & - & $22-0 \mathrm{ka} \mathrm{BP}$ \\
\hline TraCE-GHG & - & Transient & - & - & $22-0 \mathrm{ka} \mathrm{BP}$ \\
\hline TraCE-MWF & - & - & Transient & - & $19-0 \mathrm{ka} \mathrm{BP}$ \\
\hline TraCE-ICE & - & - & - & Transient & $19-0 \mathrm{ka} \mathrm{BP}$ \\
\hline
\end{tabular}

seasonal migration of the intertropical convergence zone (ITCZ), and thus the submonsoon systems may exhibit similar behaviors in response to the ITCZ change on different time scales. For example, Northern Hemisphere land monsoon rainfall shows a similar decadal variation over the last century (Zhou et al. 2008; B. Wang et al. 2018). Geological evidence and climate models indicated a weakened and strengthened global monsoon land precipitation in the LGM and Holocene, respectively (Jiang et al. 2015a,b). These studies all suggest that the African-Asian monsoon systems may exhibit an overall similar response to the same external forcings, while the relative role of individual forcing is not fully investigated. In addition, existing studies mainly focus on the role of atmospheric circulations in modulating precipitation or humidity. However, the temperature changes could also alter the moisture content in the atmosphere, which is an important factor responsible for precipitation change (Chou et al. 2013). Therefore, two important scientific questions should be further explored: 1) whether the Asian and African monsoonal precipitation variations are synchronous over the last $21 \mathrm{ka}$ in response to different external forcings and 2) what are the relative contributions of changes in monsoon circulation (i.e., dynamic effect) and atmospheric humidity (i.e., thermodynamic effect) to precipitation change. Resolving these issues may help us further understand the evolution of the AAMP and shed light on the behavior of the AAMP in the long-term future.

Here, we use a set of fully coupled transient climate simulations spanning the last $21 \mathrm{ka}$ to examine the evolution of the AAMP. This study aims to isolate and compare the influences of orbital insolation, GHGs, and ice sheets on the AAMP and to examine the contributions of atmospheric circulation and humidity to precipitation change. The remainder of the paper is organized as follows. In section 2 , we introduce the transient simulations and the methods used. In section 3 , we discuss the dominant mode of the modeled AAMP over the last $21 \mathrm{ka}$ and its response to different external forcings. The moisture budget for the AAMP changes is analyzed in section 4 , and we summarize the study and discuss the potential uncertainties in section 5 .

\section{Method}

We take advantage of the simulations of transient climate evolution over the last $21 \mathrm{ka}$ ("TraCE-21ka") using the Community Climate System Model, version 3 (Table 1). The TraCE-21ka includes a full-forcing simulation (hereinafter TraCE-full), which is forced with the transient orbital-induced insolation (Berger 1978), GHG concentrations (Joos and Spahni 2008), meltwater fluxes (He 2011), and ice sheet topography and extent (Peltier 2004) (Fig. 1). In addition, four corresponding single-forcing sensitivity simulations are conducted, each of which is driven by only one of the forcings in the TraCE-full experiment, and the other forcings or boundary conditions are fixed at the start of each simulation (hereinafter TraCE-ORB, TraCEGHG, TraCE-MWF, and TraCE-ICE, respectively). The TraCE-full has been shown to reproduce many aspects of the climate evolution since the LGM based on geological evidence, such as El Niño (Liu et al. 2014b), tropical cyclones (Yan and Zhang 2017), the East Asian monsoon (Liu et al. 2014a; Wen et al. 2016), the African precipitation (Shanahan et al. 2015), and several abrupt climate shifts (Liu et al. 2009; Tierney et al. 2016). Detailed information about the TraCE$21 \mathrm{ka}$ simulations is given in $\mathrm{He}$ (2011). Generally, the TraCE-full largely reproduces the observed AfricanAsian summer precipitation and lower-level atmospheric circulations (Fig. S1 in the online supplemental material), although some biases exist. For instances, the observations suggest that excessive summer precipitation occurs in South Asia and reduces from the coast to inland, while the simulated precipitation concentrates in central China.

We use monthly outputs and decadal-mean seasonal outputs of the TraCE-full and four sensitivity experiments, respectively. The Asian-African monsoon domain is defined as the region in which the annual range [June-August (JJA) minus December-February (DJF)] of precipitation exceeds $180 \mathrm{~mm}$ and the summer (JJA) 


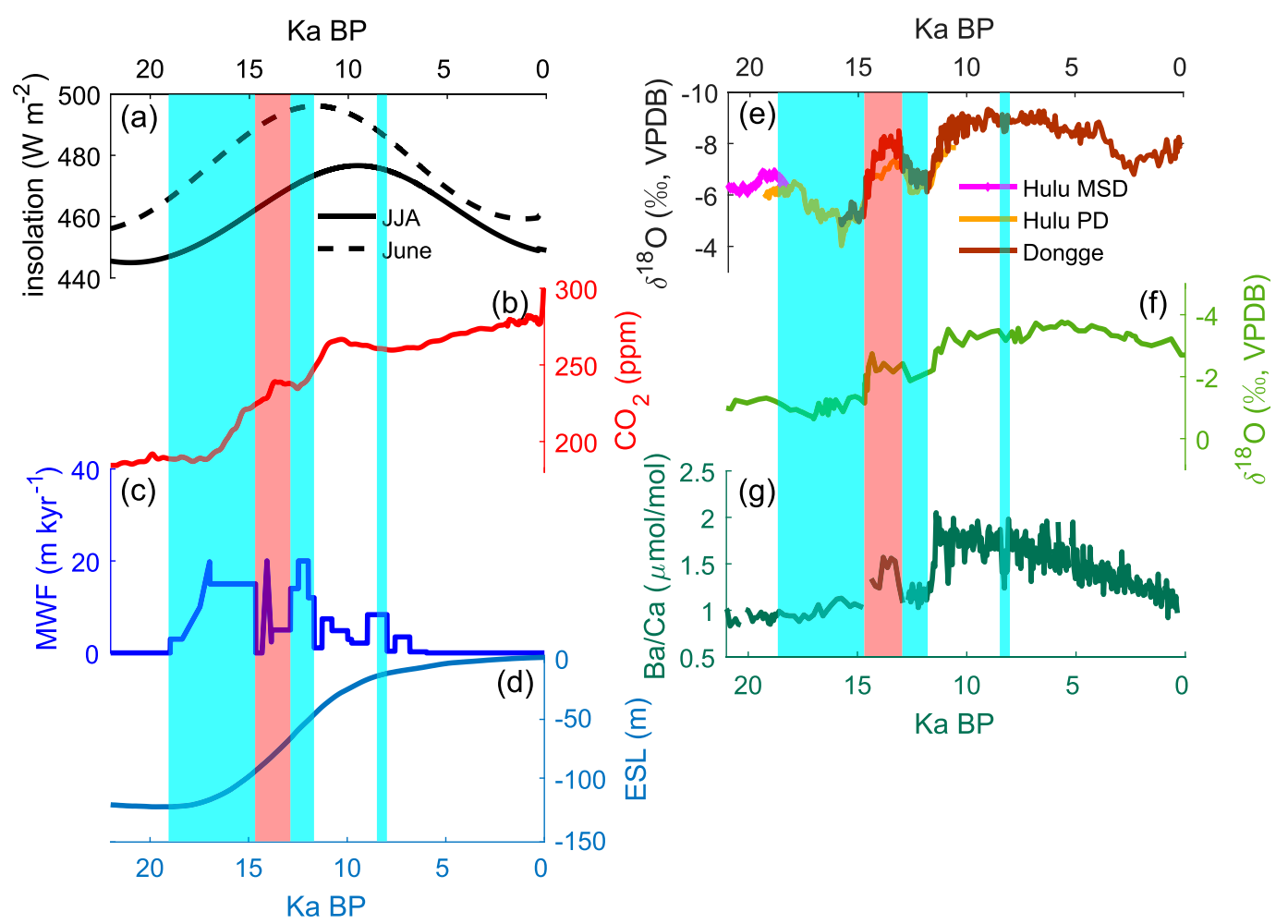

FIG. 1. Evolution of external forcings applied in (left) the TraCE-21ka simulation and (right) reconstructions for the AAMP: (a) insolation of summer (JJA average; solid curve) and June (dashed curve) over the Asian-African monsoon domain, (b) $\mathrm{CO}_{2}$ concentration, (c) meltwater fluxes in the Northern Hemisphere, (d) modeled eustatic sea level, (e) the East Asian monsoon records from Chinese cave stalagmites (Wang et al. 2001; Yuan et al. 2004), (f) the Indian monsoon record from a marine sediment in northern Bay of Bengal (Kudrass et al. 2001), and (g) the North African monsoon record from a marine sediment in the Gulf of Guinea (Weldeab et al. 2007). Three cold events (Heinrich Stadial 1, Younger Dryas, and $8.2 \mathrm{ka}$ ) and a warm event (Bølling-Aller $\varnothing$ ) are marked as the blue and red vertical panels, respectively.

precipitation exceeds $35 \%$ of the annual precipitation (Zhou et al. 2008). The AAMP was defined as the land summer precipitation in the Asian-African monsoon domain. It is noteworthy that part of southeastern China does not match the monsoon definition in both observations and simulations (Fig. S1; Wang et al. 2012; Lee and Wang 2014). This is attributed to the fact that East Asian subtropical monsoon establishes quite early in mid-March (Qi et al. 2008), bringing plentiful precipitation in southeastern China and reducing the ratio between summer and annual precipitation. Therefore, we still consider southeastern China as a monsooninfluenced region here. Although the boundary of monsoon domain varies with time over the last $21 \mathrm{ka}$ (online supplemental Fig. S2), the variation of the total AAMP is insensitive to the migration of monsoon domain. Thus, we use the fixed modern monsoon domain in the following analysis. An empirical orthogonal function (EOF) is applied to the summer precipitation to obtain the dominant mode of the AAMP from the LGM to the present. We perform a 100-yr running averaging on the precipitation to emphasize its millennial variability before carrying out the EOF.

Several monsoon indices are used to quantify the changes in monsoon circulations. The North African summer monsoon index (NAFSMI) is defined as the lower-level westerly [U850; these variables refer to the east-west (U) and north-south (V) wind components and the pressure level in hectopascals] over $0^{\circ}-15^{\circ} \mathrm{N}$ and $30^{\circ} \mathrm{W}-30^{\circ} \mathrm{E}$ (Yim et al. 2014). For the South Asia summer monsoon (SASM), two indices are used: 1) the vertical shear of southerlies (V850 - V200) over $10^{\circ}-30^{\circ} \mathrm{N}$ and $70^{\circ}-110^{\circ} \mathrm{E}$ (SASMVI; Goswami et al. 1999) and 2) the vertical shear of easterlies (U850 U200) averaged over $5^{\circ}-20^{\circ} \mathrm{N}$ and $40^{\circ}-80^{\circ} \mathrm{E}$ (SASMUI; Wang and Fan 1999), both of which are closely tied to the convection activity over India and Bay of Bengal. In addition, the East Asia summer monsoon index (EASMI) is defined as the lower-level southerly (V850) over $30^{\circ}-45^{\circ} \mathrm{N}$ and $100^{\circ}-120^{\circ} \mathrm{E}$ (Wen et al. 2016). 
To estimate the relative importance of the thermal and dynamic contributions to precipitation change between two periods, we refer to the column-integrated moisture budget equation (Chou et al. 2013)

$$
\begin{aligned}
P^{\prime} & =-\langle\nabla \cdot \mathbf{V} q\rangle^{\prime}+E^{\prime}+\delta \\
& =-\langle q \nabla \cdot \mathbf{V}\rangle^{\prime}-\langle\mathbf{V} \cdot \nabla q\rangle^{\prime}+E^{\prime}+\delta,
\end{aligned}
$$

where $P$ is the precipitation, $q$ is the specific humidity, $\mathbf{V}$ is the horizontal velocity, $E$ is the evaporation, the prime denotes the climatological differences between two periods, and angle brackets represent column integration from the surface to $300 \mathrm{hPa}$. The residual term $\delta$ includes transient eddies, nonlinear effects, and moisture storage. By assuming that the pressure velocity $\omega$ is zero at the surface and tropopause and dividing the moisture advection into thermodynamic and dynamic components, the moisture budget equation can be written as

$P^{\prime}=-\left\langle\bar{\omega} \partial_{p} q^{\prime}\right\rangle-\left\langle\omega^{\prime} \partial_{p} \bar{q}\right\rangle-\left\langle\overline{\mathbf{V}} \cdot \nabla q^{\prime}\right\rangle-\left\langle\mathbf{V}^{\prime} \cdot \nabla \bar{q}\right\rangle+E^{\prime}+\delta$,

where the overbar represents the climatology in the latter period, the terms $-\left\langle\bar{\omega} \partial_{p} q^{\prime}\right\rangle$ and $-\left\langle\omega^{\prime} \partial_{p} \bar{q}\right\rangle$ are the thermodynamic and dynamic components of vertical moisture advection, respectively, and $-\left\langle\mathbf{V} \cdot \nabla q^{\prime}\right\rangle$ and $-\left\langle\mathbf{V}^{\prime} \cdot \nabla \bar{q}\right\rangle$ are the thermodynamic and dynamic contributions of horizontal moisture advection, respectively. It is clear that the thermodynamic term is related to the change in humidity, which is constrained by temperature anomalies according to the Clausius-Clapeyron relationship. The dynamic term is directly induced by velocity anomalies, that is, the change in circulation due to temperature changes.

\section{Results}

\section{a. Dominant mode of the AAMP over the last $21 \mathrm{ka}$}

We examine the main characteristics of the AAMP variation in the TraCE-full experiment in Fig. 2a. The first EOF mode of the AAMP explains $\sim 69 \%$ of its total variance, so we focus on this mode to investigate its spatiotemporal variation. The dominant spatial pattern broadly shows a uniform positive anomaly over Asia and tropical North Africa, with the exception of central China and the southern edge of the North African monsoon domain. The principal component (PC) generally increases from the LGM to $\sim 15 \mathrm{ka} \mathrm{BP}$, fluctuates greatly between 15 and $10 \mathrm{ka} \mathrm{BP}$, which covers the Bølling-Allerød (BA) and Younger Dryas (YD) events, and then decreases throughout the Holocene (Fig. 2b), in good agreement with the AAMP reconstructions (Figs. 1e-g). The dominant AAMP pattern demonstrates that variations of the Asian and tropical North African monsoon precipitation are largely synchronous at the orbital time scale. We further perform EOFs for the North African, Indian, and East Asian summer monsoonal precipitation, respectively (online supplemental Fig. S3). The results further confirm the synchronous variation of individual monsoon systems during the last $21 \mathrm{ka}$, although regional differences exist.

On average, the AAMP was higher and lower in the LGM and the early/middle Holocene, respectively, relative to the present. This result is consistent with numerous reconstructions (e.g., Wang et al. 2008; Cai et al. 2015; Lu et al. 2013) and equilibrium simulations (Jiang et al. 2015a; Yan et al. 2016). In addition, several abrupt changes in the AAMP recorded in proxies are detected in the TraCE-full experiment, such as the continual decrease in precipitation during the Heinrich Stadial 1 (HS1) and the YD in each submonsoon region. Although the PC peaks at approximately $10 \mathrm{ka}$ BP during the Holocene, the differing EOF loadings over the monsoon regions indicate that the timings of the maximum precipitation are spatially dependent, which is also argued as the asynchronous Holocene optimum in reconstruction studies (Wang et al. 2010; Caley et al. 2011). In general, the TraCE-full experiment produces reasonable AAMP changes in several key periods (i.e., the LGM and Holocene) compared with geological evidence and previous modeling studies, giving us confidence to explore the responses of the AAMP to different forcings in the sensitivity experiments and the associated dynamic mechanisms.

\section{b. Role of orbital forcing}

The dominant AAMP mode in the TraCE-ORB experiment shows a nonuniform spatial distribution over Asia and Africa with positive anomalies over North China, India, and the northern part of the North African monsoon region but negative anomalies over South China and the southern part of the North African monsoon region (Fig. 2c), which is different from the results of the TraCE-full experiment. The corresponding PC has a significant increasing trend from the LGM to the early Holocene, peaking at $\sim 12-11 \mathrm{ka} \mathrm{BP}$, then decreases gradually to the present day (Fig. 2d). Such variation may largely follow the June insolation rather than the mean summer insolation (Fig. 1a), indicating that the orbital insolation probably has a "delay effect" on the AAMP. Note that the ice sheets are fixed at their LGM extent in the TraCE-ORB but retreated significantly during the Holocene in the TraCE-full; this 

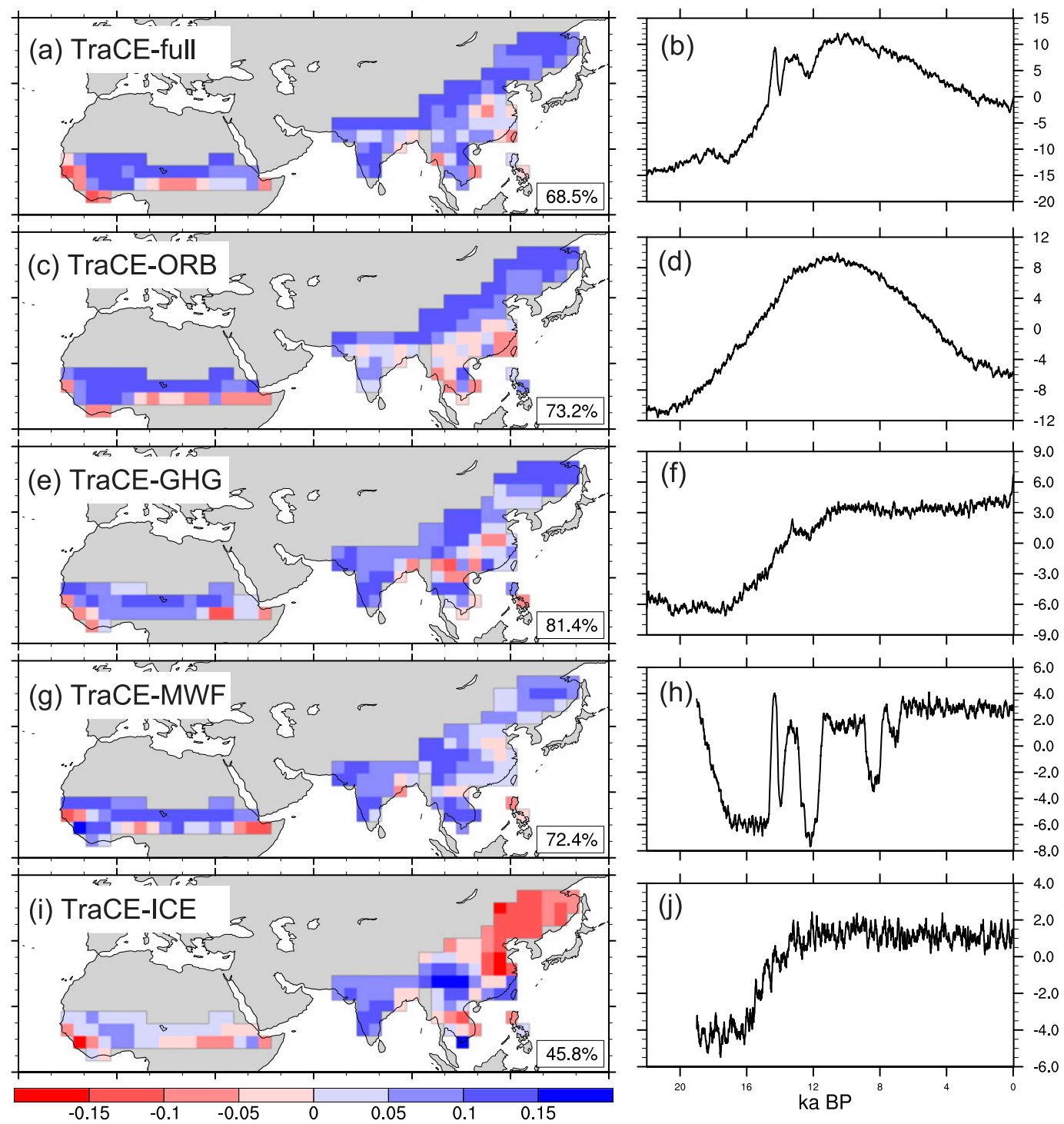

FIG. 2. The first EOFs of AAMP in the (a),(b) TraCE-full, (c),(d) TraCE-ORB, (e),(f) TraCE-GHG, (g),(h) TraCE-MWF, and (i),(j) TraCE-ICE, showing (left) the spatial mode and (right) the corresponding principal component.

difference in the boundary conditions may contribute to the phase mismatch between the PCs in the TraCE-full and TraCE-ORB, which is consistent with reconstruction studies that ice sheets play an important role in the relationship between orbital insolation and the Asian monsoon (Fleitmann et al. 2007; Chen et al. 2008). Next, we discuss how changes in orbital insolation modulate largescale atmospheric circulation and hence the AAMP.

In the early Holocene, Northern Hemisphere insolation in June has a uniformly increasing pattern relative to the present day, with the anomalies increasing with latitudes (Fig. 3). Such changes in orbital insolation lead to strong warming over the subtropical and weak warming over the tropical regions (Fig. 4a), which gives rise to an enhanced meridional thermal contrast. The warming over East Asia continent is stronger than the adjacent subtropical western Pacific due to their different heat capacity, enhancing the zonal thermal contrast. As a result, the East Asian summer monsoon reinforces (Table 2). In addition, the strongest warming over Asia occurs in the midlatitudes, indicative of reduced (enhanced) the temperature contrast between the midlatitude (high latitude) and subtropical (midlatitude) regions. Consequently, the upper-level zonal winds are weakened in the subtropical region while being strengthened in the extratropical region according to the 


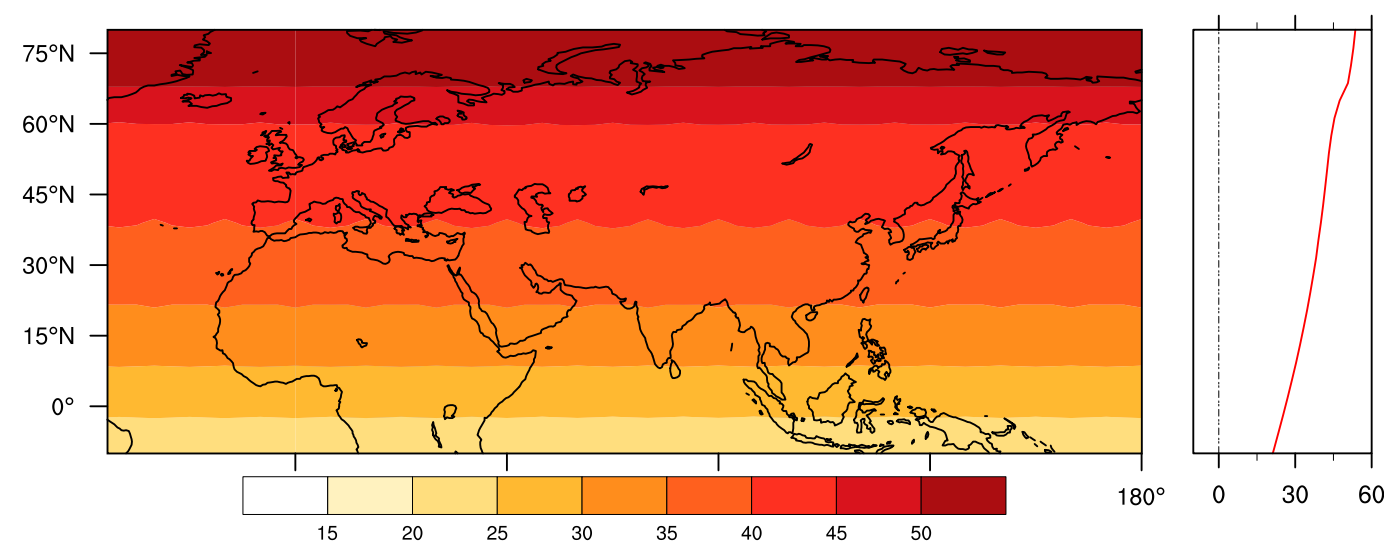

FIG. 3. (left) Differences in June insolation $\left(\mathrm{W} \mathrm{m}^{-2}\right)$ in the TraCE-ORB between 12-11 and 1-0 ka BP, along with (right) its zonal average.

principle of thermal wind (Fig. 4c). This result implies a northward movement of the westerly jet and hence a northward shift of the East Asian subtropical monsoon and rain belt (Yu et al. 2004; Lin and Lu 2005).

The North Africa and Indian monsoons can be characterized by the vertical wind shear between lower westerlies and upper easterlies (Fig. S1 and Fig. 4c; Webster and Yang 1992). As shown in Fig. 5b, the lowerlevel cross-equatorial flows are enhanced over tropical Indian Ocean and North Africa due to the increased temperature contrast between the Northern and Southern Hemispheres. The upper-level easterlies are also strengthened (Figs. 4a,c). As a result, the Indian and North Africa summer monsoons get stronger in response to the increased orbital forcing. In addition, the enhancement of local overturning over South Asia, which is associated with the local Hadley cell, also is conducive to a strengthened Indian summer monsoon (Table 2).

To sum up, the changes in meridional temperature and lower-upper circulations favor a general northward migration of the ITCZ (Fig. 5a), facilitating moisture transport to the Asian-African monsoon regions. The water vapor converges over North China, India, and tropical North Africa but diverges over South China, enhancing and lessening the precipitation over these regions, respectively (Figs. 4d and 6a).

\section{c. Role of GHGs}

In the TraCE-GHG, the dominant spatial pattern of the AAMP exhibits positive anomalies over most of the Asian-African monsoon regions and negative anomalies only over southeastern Asia (Fig. 2e), which resembles the results of the TraCE-full except for South China. The corresponding PC is negative from the LGM to $16 \mathrm{ka} \mathrm{BP}$, increases rapidly to a positive level at approximately $10 \mathrm{ka} \mathrm{BP}$, and remains there to the present
(Fig. 2f), which is highly correlated with the variation in $\mathrm{CO}_{2}$ concentrations since the LGM (Fig. 1b). The higher GHG concentrations in the late Holocene relative to the LGM exacerbate the greenhouse effect and warm the Earth significantly. However, the warming at high latitudes is stronger than that at low latitudes due to the polar amplification effect (Fig. 7a).

Such changes in temperature indicate a northward shift of ITCZ (Fig. 5b). As a result, the lower-level crossequatorial flows are enhanced over tropical North Africa and Indian Ocean, and the upper-level easterlies are also strengthened, indicating reinforced Indian and tropical North African monsoons (Table 2; Webster and Yang 1992; Wang and Fan 1999; Wang et al. 2013), which bring moisture from tropical oceans to the continents and hence more precipitation. Moreover, the anomalous southeasterly over India and the Bay of Bengal favors a strengthened local Hadley circulation, and hence deeper convection (Goswami et al. 1999) and more rainfall over India (Fig. 6b). Similar to the TraCEORB, the East Asian subtropical monsoon is enhanced in response to the increased meridional and zonal temperature contrast (Fig. 7b). The northward migration of upper-level westerly jet (i.e., an increase in the north of its axis and a decrease to the south) over East Asia due to the thermal gradient change also promotes the East Asian subtropical monsoon (Fig. 7c). As a result, moisture converges more in North China, favoring more precipitation there (Figs. $6 \mathrm{~b}$ and $7 \mathrm{~d}$ ). Although moisture diverges over South China, precipitation is still increased, which may be attributed to the enhanced vertical humidity change and local evaporation (see details in section 4).

In general, the physical mechanisms of the variations in GHGs and insolation driving the AAMP changes are very similar, but the response of the AAMP and the 
Differences: 12-11 ka BP - 1-0 ka BP in TraCE-ORB
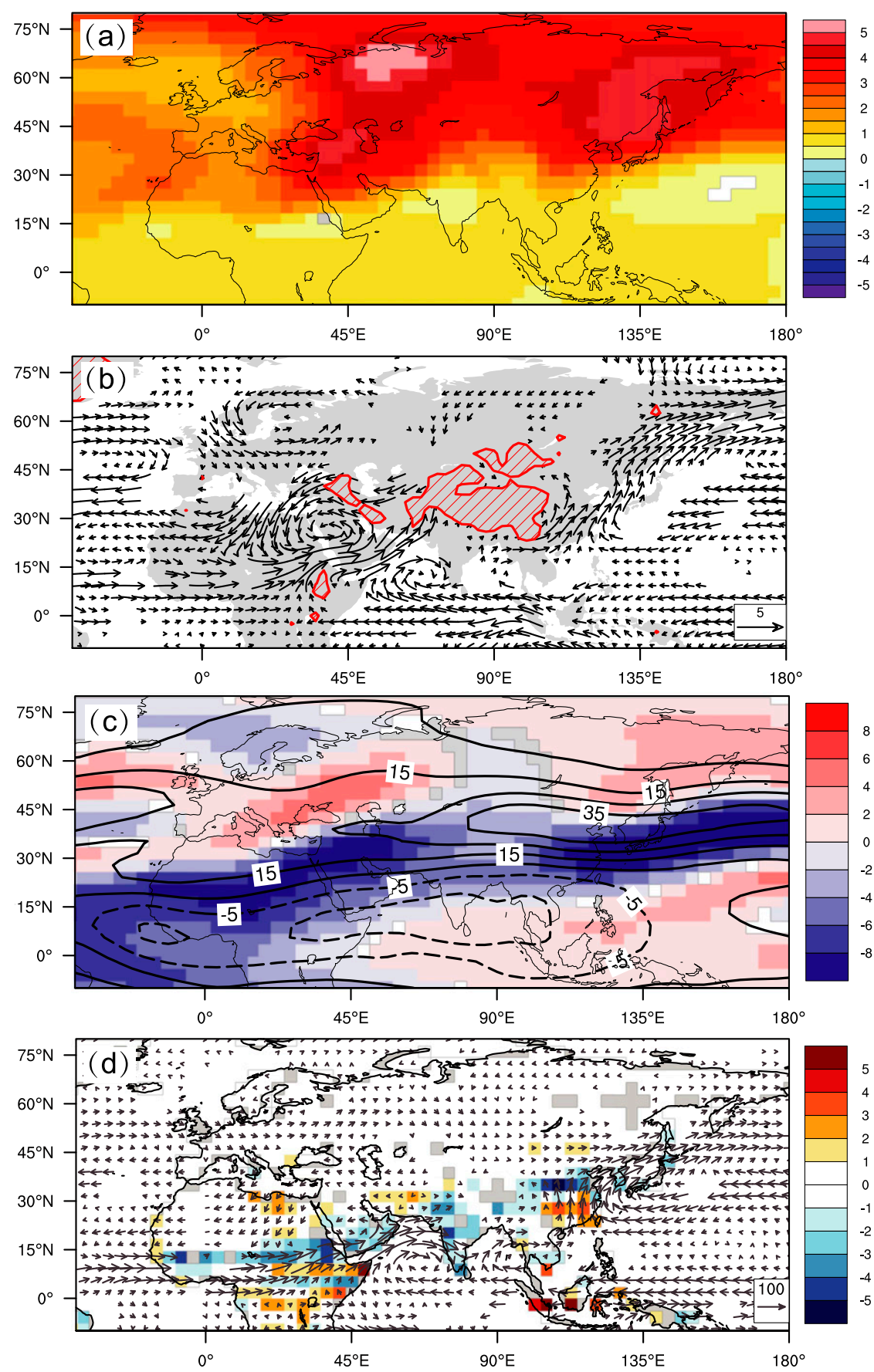

FIG. 4. Anomalies of (a) tropospheric temperature (1000-300 hPa; $\left.{ }^{\circ} \mathrm{C}\right)$, (b) 850-hPa winds $\left(\mathrm{m} \mathrm{s}^{-1}\right)$, (c) 200-hPa zonal winds (shading; $\mathrm{m} \mathrm{s}^{-1}$ ), and (d) column-integrated water vapor (1000-300 $\left.\mathrm{hPa} ; \mathrm{kg} \mathrm{m}^{-1} \mathrm{~s}^{-1}\right)$ and its divergence $\left(10^{-5} \mathrm{~kg} \mathrm{~m}^{-1} \mathrm{~s}^{-2}\right)$ between two periods (shown at the top) in the TraCE-ORB. The contours in (b) are the climatological 200-hPa zonal winds $\left(\mathrm{m} \mathrm{s}^{-1}\right)$. Only differences that are significant at the $95 \%$ level are shown, and areas with elevation below $1500 \mathrm{~m}$ are outlined by red boundaries in (b). 
TABLE 2. Anomalies of monsoon indices (in $\mathrm{m} \mathrm{s}^{-1}$ ) between two key periods in individual sensitivity experiments. The differences that are significant at $95 \%$ level are in boldface type, and the italic values represent the differences between standardized indices. The two periods in individual sensitivity experiments are 12-11 and 1-0 ka BP in TraCE-ORB, 1-0 and 19-18 ka BP in TraCE-GHG, 14.5-13 and 17-16 ka BP in TraCE-WMF, and 13-12 and 19-18 ka BP in TraCE-ICE.

\begin{tabular}{lcccc}
\hline \hline & TraCE-ORB & TraCE-GHG & TraCE-MWF & TraCE-ICE \\
\hline NAFSMI & $\mathbf{1 . 9 7}$ & $\mathbf{0 . 9 5}$ & $\mathbf{0 . 3 1}$ & $\mathbf{- 0 . 1 5}$ \\
SASMVI & $\mathbf{1 . 0 4}$ & $\mathbf{0 . 6 8}$ & $\mathbf{0 . 3 3}$ & $\mathbf{1 . 1}(\mathbf{2 . 3 9})$ \\
SASMUI & $\mathbf{1 . 9 1}$ & $\mathbf{1 . 6 5}$ & $\mathbf{2 . 3}$ & $\mathbf{- 0 . 4 9 ( - \mathbf { 1 . 0 } )}$ \\
EASMI & $\mathbf{0 . 9 3}$ & $\mathbf{0 . 3 4}$ & 0.07 & $\mathbf{- 0 . 2 2}$ \\
\hline
\end{tabular}

associated circulations to the GHG concentrations is more moderate than that to orbital insolation.

\section{d. Role of meltwater forcing}

The TraCE-MWF experiment shows an almost unanimous spatial variation in the dominant AAMP pattern (Fig. 2g), similar to the full-forcing experiment but with weaker loadings over East Asia. The corresponding PC shows abrupt and large-amplitude fluctuations, which are closely tied to the changes in meltwater fluxes in the Northern Hemisphere (Figs. 1c and 3h). As a result, although the PC in the TraCE-full experiment shows a significant long-term trend controlled by insolation changes, several abrupt impulses can be explained by the changes in meltwater discharge, such as during the HS1 and YD events (Fig. 2b).

To explore the influence of meltwater discharge on the AAMP, we select the BA $(\sim 14.5 \mathrm{ka} \mathrm{BP})$ as a reference


FIG. 5. Regionally zonal mean $\left(40^{\circ} \mathrm{W}-150^{\circ} \mathrm{E}\right)$ meridional streamfunction averaged over $1000-300 \mathrm{hPa}$ $\left(10^{9} \mathrm{~kg} \mathrm{~s}^{-1}\right)$ in two periods (shown in the right bottom of each panel) in individual sensitivity experiments. Positive and negative values represent clockwise and counterclockwise circulation, respectively; therefore, the latitudes of zero values in the subtropics (open circles) can be used to measure the location of the regional ITCZ (Schneider et al. 2014; Byrne et al. 2018). 

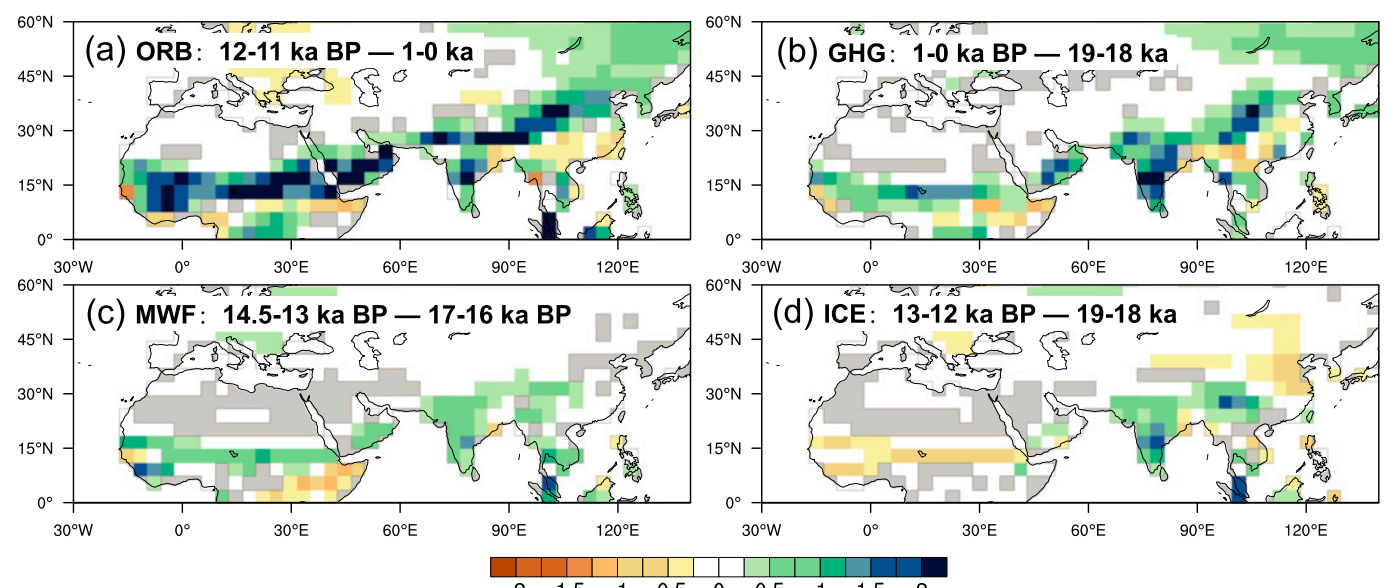

FIG. 6. Anomalies of precipitation $\left(\mathrm{mm} \mathrm{day}^{-1}\right.$ ) between two periods (shown in the left top of each panel) in individual sensitivity experiments. Only differences that are significant at the $95 \%$ level are shown.

period during which meltwater discharge into the North Atlantic Ocean decreases. In comparison with the HS1 event ( $\sim 16 \mathrm{ka} \mathrm{BP})$, the decrease in meltwater discharge increases the surface seawater salinity in the North Atlantic, enhancing the Atlantic meridional overturning circulation (AMOC) (Carlson et al. 2008; Liu et al. 2009; $\mathrm{Ba}$ et al. 2014). The strengthened AMOC further reinforces the northward heat transport between the two hemispheres, leading to an overall warming of the Northern Hemisphere, especially in high-latitude regions (Fig. 8a). Such interhemispheric temperature changes cause the ITCZ to move northward (Fig. 5c) and result in a generally intensified Northern Hemisphere summer monsoons.

In addition, the upper-level tropical easterly jet is also increased over North Africa (Fig. 9c), coupling with enhanced low-level westerly, which is beneficial for the North African monsoonal precipitation (Wang et al. 2013). For the Indian precipitation, although the local easterly wind anomaly does not contribute to an enhanced climatological Indian summer monsoon, the precipitation is increased due to the strengthened westerlies over Arabian Sea (Fig. 8b; Wang and Fan 1999). In addition, as revealed in the TraCE-GHG, the anomalous southeasterly over India and Bay of Bengal is associated with an enhanced local overturning (Table 2), leading to more precipitation over India (Fig. 6c). The increased precipitation further reduces the surface net energy and results in the cooling over India (Fig. 8a; Pausata et al. 2011). Therefore, the local ITCZ over India does not show a clear northward migration, and the southwesterly over Indian peninsula is not enhanced as expected. For East Asia, the response of low- and upper-level circulation to meltwater forcing is very weak (Table 2; Figs. 8 b,c), with no significant precipitation change there.
Overall, the AAMP is strengthened in the BA relative to the HS1 mainly over North Africa and India.

\section{e. Role of ice sheets}

The retreat of ice sheets affects the climate not only by altering the meltwater discharge but also by changing Earth's orography. In the TraCE-ICE experiment, the Asian monsoon precipitation shows an obvious dipole anomaly pattern: negative over North China and positive over India and southwestern China (Fig. 2i). The EOF results show no significant change over tropical North Africa, indicating a limited impact of the ice sheets. The corresponding PC is decreased from a negative phase in the LGM to a positive phase in the early Holocene, which remains to the present day (Fig. 2j). Combining the spatial and temporal changes in the AAMP, we find that when the topography of the ice sheets is lower, the summer precipitation over India and southwestern China is increased, whereas the precipitation over North China is decreased (Fig. 6d).

The possible mechanisms could be as follows. Foremost, the lowering of the ice sheets can lead to a northward shift of the Northern Hemisphere westerlies (Figs. 9b,c), resulting in an expansion of sea ice. The expanded sea ice insulates the ocean from heat loss and leads to a weakening in the AMOC (Zhu et al. 2014; Yan and Zhang 2017). As discussed above, the weakened AMOC further reduces the heat transport from the Southern Hemisphere to high-latitude regions in the Northern Hemisphere. Therefore, the Northern Hemisphere generally becomes colder (Fig. 9a) and leads to a southward movement of the ITCZ, decreasing the North African monsoonal precipitation (Fig. 6d). However, the surface albedo is decreased as ice sheets melt, which results in more incoming radiation and warms North 

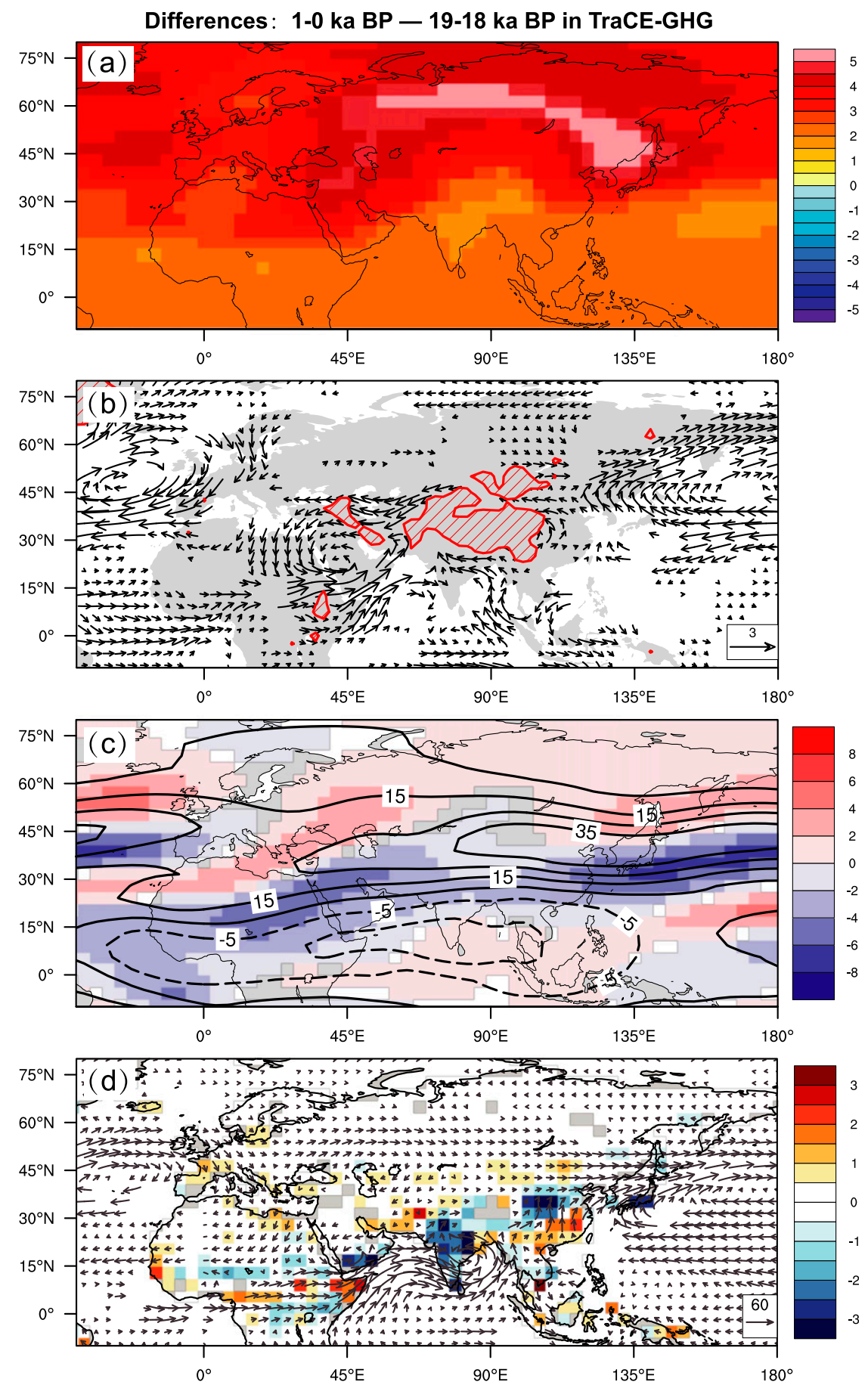

FIG. 7. As in Fig. 4, but in the TraCE-GHG.

America and northwestern Europe where ice sheets have existed. The northwestern Pacific warming is closely related to the northward migration of low-level westerlies caused by ice sheet melt (N. Wang et al. 2018), which strengthens the Kuroshio Extension (Figs. 9a,b). Thus, the local ITCZ over Asia shifts northward, in contrast to the global ITCZ (Fig. 5d), favoring an enhanced Indian monsoon (Fig. 9b). It is noted that although the Indian monsoon variation in TraCE-ICE has different signs between the SASMVI and SAMUI, but the precipitation is eventually increased as the amplitude of SASMVI change is much larger than the SASMUI change (Table 2). 

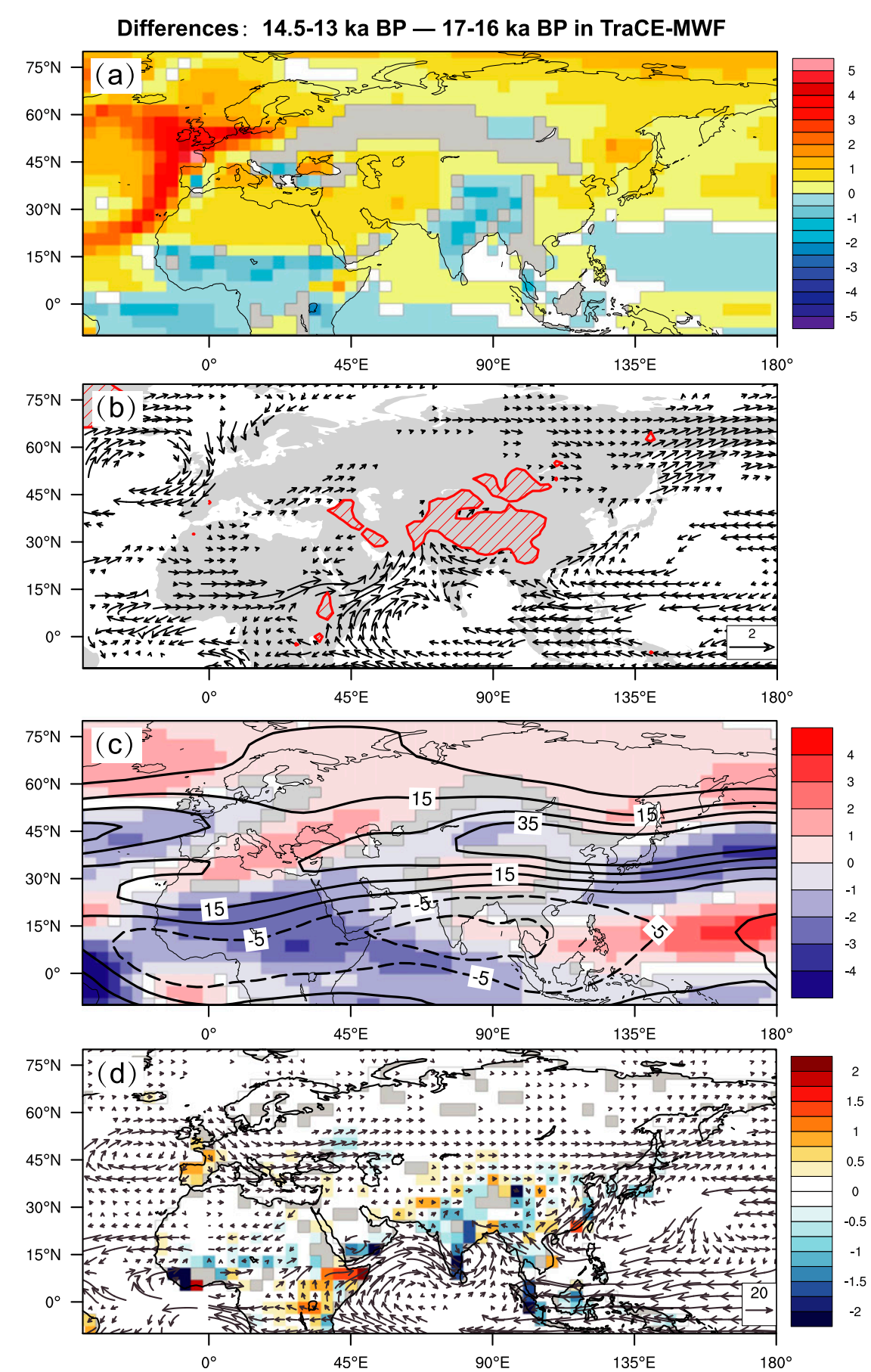

FIG. 8. As in Fig. 4, but in the TraCE-MWF and (a) is the surface temperature anomalies $\left({ }^{\circ} \mathrm{C}\right)$.

Furthermore, such a large extent of lowered ice sheets (Fig. 10a) stimulates atmospheric Rossby waves and propagates westward (Fig. 10b). There are two Rossby wave trains accounting for the East Asian precipitation change, both originating in North America. One propagates in the midlatitudes along the North Atlantic-Black Sea pathway, and the other propagates in the high latitudes through the Greenland-northwestern Europe pathway. These two waves merge and amplify because of the lowered ice sheets in northwestern Europe and eventually propagate to East Asia. The anomalous trough, expressed by the northerly and southerly anomalies over Lake Baikal and Japan, respectively, is favorable for the high-latitude cold air moving farther south. As a result, there is moisture convergence 

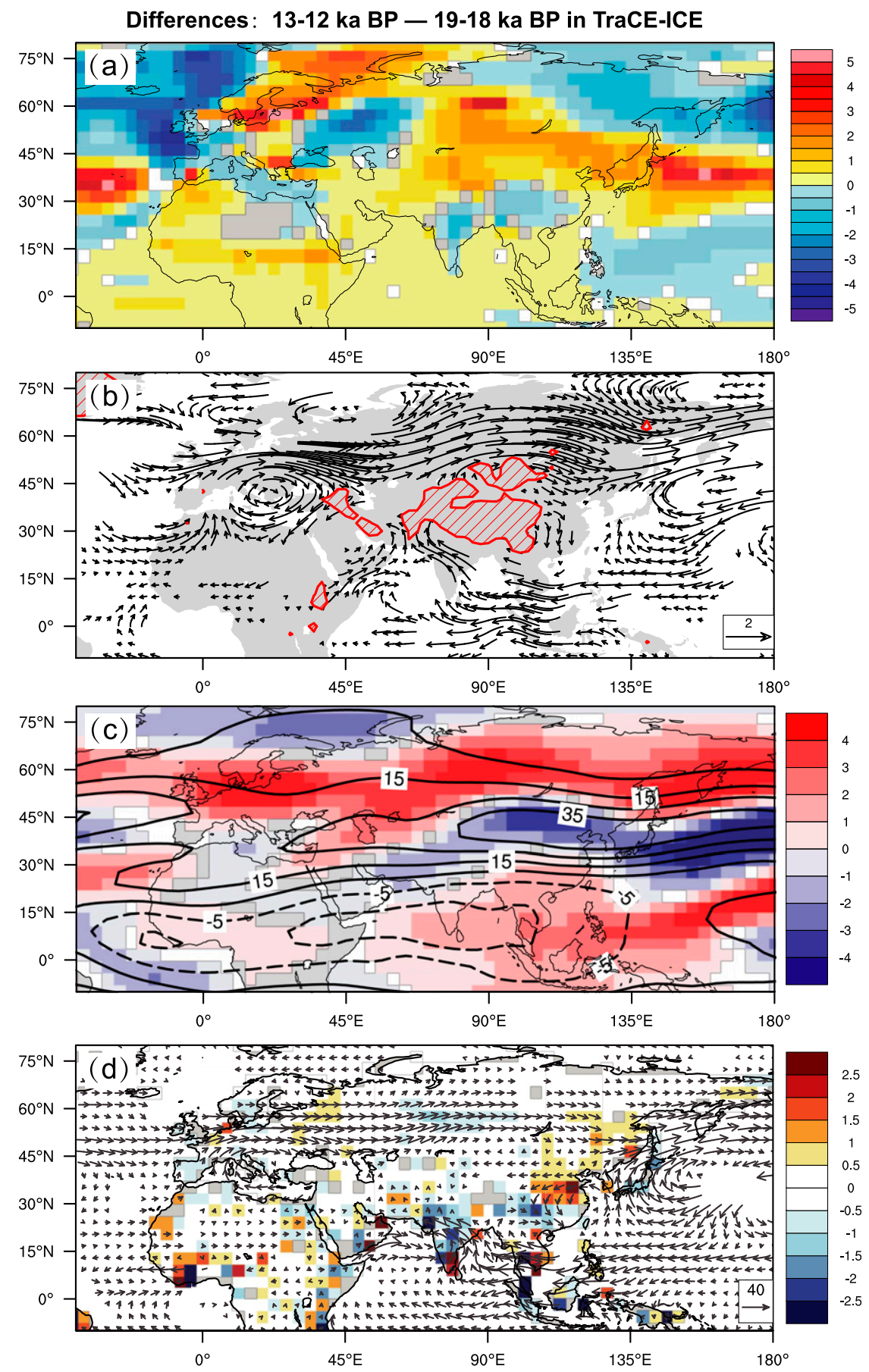

FIG. 9. As in Fig. 8, but in the TraCE-ICE.

(divergence) in South (North) China and hence abundant (inadequate) precipitation (Figs. 6d and 9d).

\section{Moisture budget analysis for the AAMP changes}

From the TraCE-21ka sensitivity experiments, we conclude that external forcings modulate the AAMP in two ways. First, external forcings affect the regional temperature, which directly alters the atmospheric moisture content through the Clausius-Clapeyron relationship and hence influences precipitation. Second, anomalous large-scale atmospheric circulation due to changes in the thermal state or topography further regulates the spatial variation in the AAMP. To 

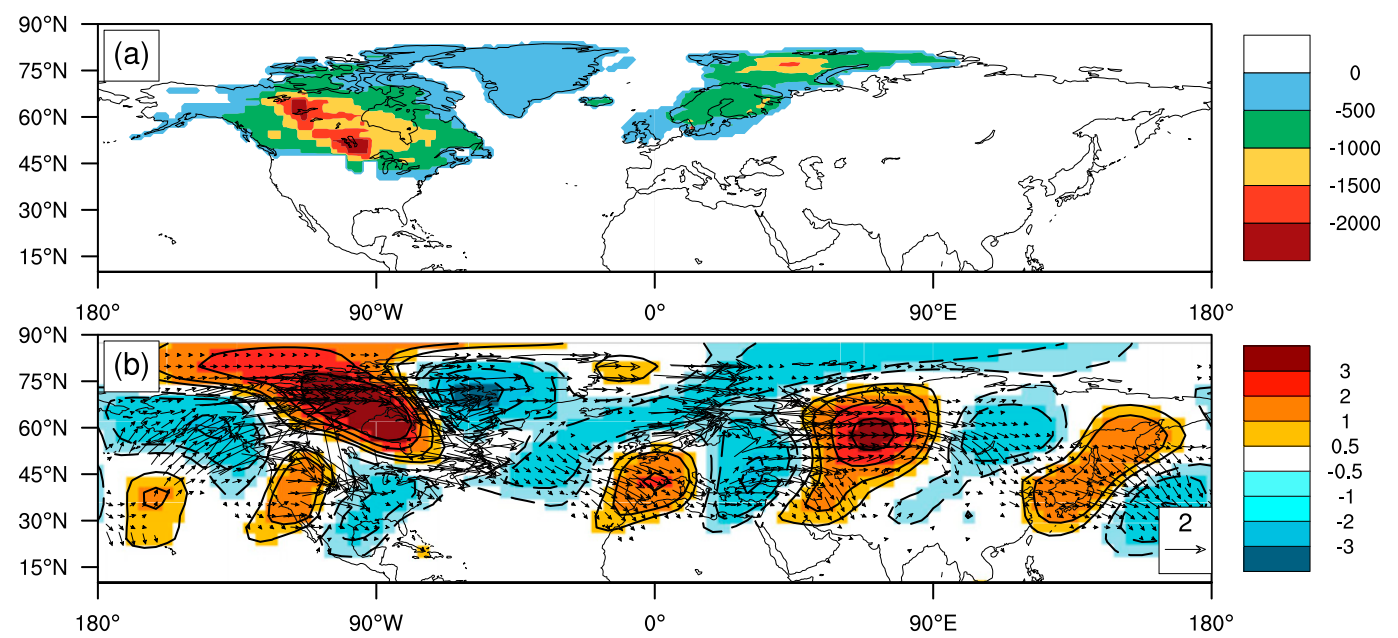

FIG. 10. Changes in the (a) thickness of ice sheets (m) in ICE-5G (VM2) and (b) 500-hPa meridional winds (shading; $\mathrm{m} \mathrm{s}^{-1}$ ) and wave activity flux (vectors; $\mathrm{m}^{2} \mathrm{~s}^{-2}$ ) in the TraCE-ICE between 13-12 ka BP and 19-18 ka BP.

estimate the relative importance of these two factors, we analyze the quantitative contributions of the thermodynamic and dynamic factors using the moisture budget equation [Eq. (2)]. Four submonsoon regions, including North China, South China, India, and tropical North Africa, are considered based on the EOF results of the sensitivity experiments.

The moisture budget analysis indicates that different external forcings have distinct effects on the four submonsoon regions. In the TraCE-ORB, the precipitation is increased over North China are mainly due to the dynamic component of horizontal moisture advection (Fig. 11a), which is consistent with the remarkable changes in horizontal circulation shown in Fig. 4. However, this component is much weaker in the TraCEGHG and leads to a smaller precipitation increase, which corresponds to the moderate change in monsoon circulation relative to the orbital-forcing experiment. In the TraCE-GHG, precipitation over North China is increased due to the dynamic component of horizontal moisture advection and the thermodynamic component of vertical moisture advection. In addition, in the TraCE-ICE, precipitation over North China is decreased due to both horizontal and vertical dynamic moisture advection, with little contribution from the thermodynamic terms. For all of the single-forcing experiments, the residual term is significant but unfavorable for precipitation over North China.

Specific to South China (Fig. 11b), although temperature is both increased due to higher insolation and GHG concentration, precipitation is decreased in the TraCE-ORB but increased in the TraCE-GHG. The most important component causing this discrepancy is the thermodynamic vertical moisture advection term, which is directly affected by changes in humidity. As shown in Figs. 4 and 7, the TraCE-GHG produces a warmer South China relative to the TraCE-ORB, which could be responsible for the stronger humidity and evaporation term. Decreased meltwater discharge enhances precipitation over South China by all terms except for the horizontal thermodynamic change. However, the retreat of the ice sheets leads to more rainfall because of the horizontal thermodynamic and vertical dynamic components, which have equivalent effects.

Over India, precipitation has almost the same change in the orbital- and GHG-forcing experiments, but the relative importance of each moisture advection component is very different (Fig. 11c). Although the dynamic horizontal moisture advection is greatly enhanced in the TraCE-GHG relative to the TraCE-ORB, the thermodynamic term is significantly weakened. This difference may give rise to the diverse temperature responses of these two external forcings. In the meltwater and ice sheet experiments, increased precipitation is mainly attributed to large-scale changes in horizontal circulation. It is worth noting that, with regard to Indian precipitation change, all of the budget terms have the same sign in different sensitivity experiments.

Over tropical North Africa, changes in large-scale horizontal advection and vertical humidity are two major components that result in precipitation changes in all of the sensitivity experiments (Fig. 11d). The orbitalinduced insolation change is the most important external forcing that influences precipitation in North Africa since the LGM. Similar to North China, the response of precipitation over tropical North Africa to increasing insolation is greater than that to higher GHGs due to the increase in horizontal dynamic moisture advection, 
(a) North China

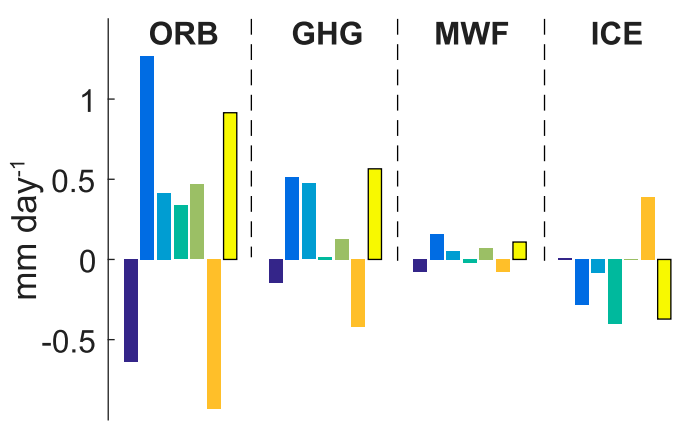

(c) India

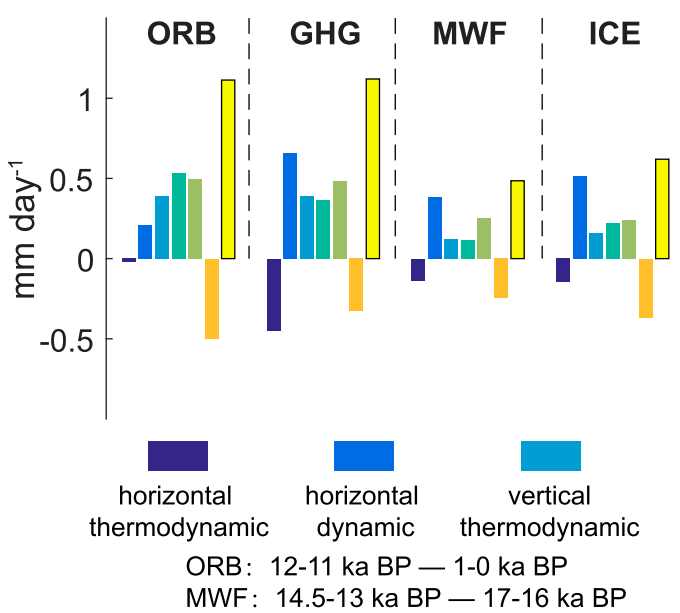

(b) South China

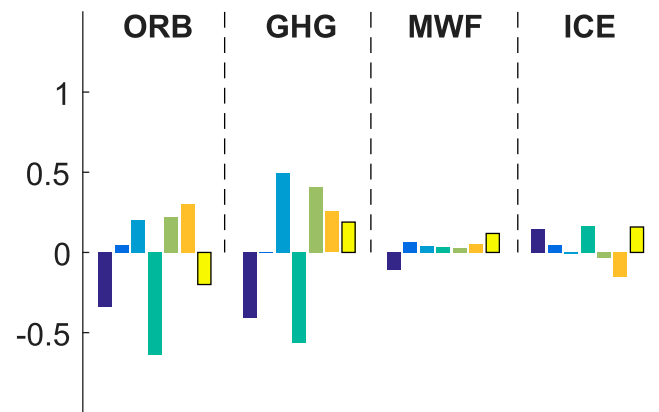

(d) Tropical North Africa

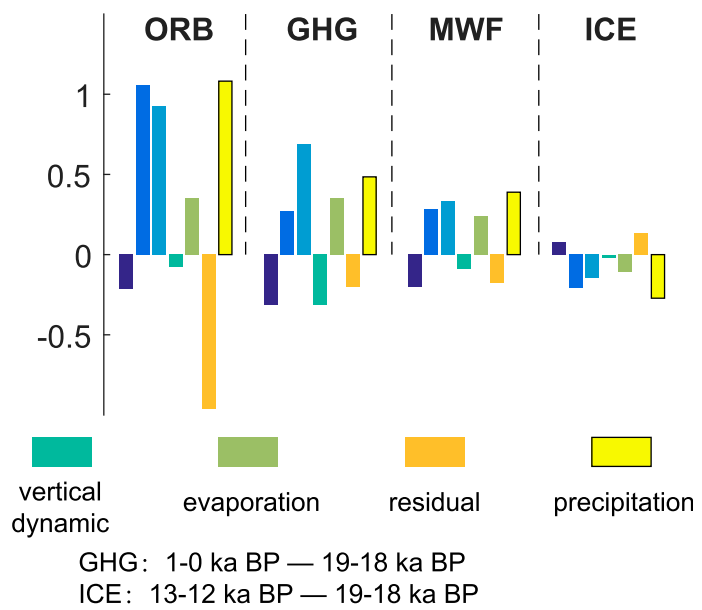

FIG. 11. Moisture budget for the precipitation changes between two periods (shown at the bottom) in four submonsoon regions: (a) North China $\left(105^{\circ}-130^{\circ} \mathrm{E}, 30^{\circ}-45^{\circ} \mathrm{N}\right)$, (b) South China $\left(100^{\circ}-120^{\circ} \mathrm{E}, 15^{\circ}-30^{\circ} \mathrm{N}\right)$, (c) India $\left(70^{\circ}-85^{\circ} \mathrm{E}, 5^{\circ}-25^{\circ} \mathrm{N}\right)$, and (d) tropical North Africa $\left(20^{\circ} \mathrm{W}-40^{\circ} \mathrm{E}, 5^{\circ}-15^{\circ} \mathrm{N}\right)$.

which also results from the enhanced temperature contrast.

\section{Summary and discussion}

In this study, we examine the influence of orbitalinduced insolation, GHG concentrations, ice sheetinduced meltwater discharge, and orography changes on the AAMP variation in a set of fully coupled transient simulations of the last $21 \mathrm{ka}$. From the LGM to the present day, the AAMP variation has the general characteristic of spatial consistency in the full-forcing experiment, indicating synchronous changes in the individual monsoon systems over the last $21 \mathrm{ka}$. In general, their synchronous variations are caused by changes in orbital insolation, GHG concentrations and meltwater forcing, and the asynchronous variations between the precipitation in North China and India are attributed to the lowering of ice sheets. In addition, the thermodynamic and dynamic contributions to the precipitation change vary not only by region but also by external forcing, implying very complicated ways that external forcings influence the precipitation in different monsoon domains.

Although the overall trend of the AAMP is dominated by insolation, the TraCE-ORB experiment shows that the change in precipitation over the northern part of the Asian-African monsoon domains is opposite to that over the southern part and has the largest anomalies on the northern edge of the monsoon regions (Fig. 2c). This result indicates that enhanced (weakened) insolation can cause a systematic northward (southward) shift of the Asian-African monsoon rain belt and a potential northward expansion (southward contraction) of the monsoon regions. This conclusion is consistent with a recent study that the Asian monsoon domain migrated farther northwest during the warm early Holocene relative to the LGM (Yang et al. 2015).

Similar to the full-forcing experiment, the TraCEGHG experiments exhibit nearly in-phase precipitation changes over the Asian-African monsoon regions, implying that GHGs have been nonnegligible drivers of 
the AAMP since the LGM. The role of GHGs may contribute to the fact that the AAMP trend in the TraCE-full experiment is more acute during the last deglaciation but more moderate during the Holocene than that in the TraCE-ORB experiment (Figs. 2b,d). The increasing trend of the AAMP during the last deglaciation is inferred to have been caused by increasing insolation and superposed by the effect of rapid GHG increase. However, the AAMP is gradually decreased during the middle to late Holocene due to precession, which was partly offset by the slow increase in GHGs.

When compared with the orbital insolation, the TraCE-GHG shows that GHGs have a larger warming effect in the Northern Hemisphere, especially at low latitudes, but induce smaller changes in the AAMP. This is because that the warming at high latitudes is amplified due to sea ice and snow cover feedbacks in response to higher insolation or GHG conditions. Nevertheless, the orbital insolation anomalies are increased with latitude (Fig. 3), but the $\mathrm{CO}_{2}$ change is generally uniform globally in the TraCE-21ka simulations. Therefore, the TraCE-GHG produces a warmer Northern Hemisphere, but the temperature contrast between high and middle latitudes is smaller than in the TraCE-ORB, which results in a moderate ITCZ shift (Figs. 5a,b) and hence weaker AAMP changes. The GHGs rose slowly before the industrial revolution but much faster subsequently. Therefore, the AAMP's response to faster GHGs change in the future may be much greater than we speculated from the last $21 \mathrm{ka}$.

Furthermore, geological evidence also indicates that the East Asian and Indian monsoons are generally weakened during HS1, which is not captured well in the TraCE-full but is clearly seen in freshwater forcing experiment. A possible explanation for the weak response in HS1 in TraCE-full is that, during the HS1, although the AAMP may be decreased greatly as a result of increased meltwater discharge, it is largely obscured by the combined effect of the rapidly increasing orbital insolation and GHGs and ice sheets lowering. However, the nonlinear interactions of individual forcings in TraCE-full cannot be ignored, which may reduce the AAMP response to meltwater forcing (online supplemental Fig. S4). By contrast, the AAMP change during YD is relatively significant in the TraCE-full. It is possibly because of, during YD, orbital forcing approaches its peak with a very small curvature, and GHG concentrations are at a relatively stable level (Figs. 2d,f), thus highlighting the AAMP reduction due to increased meltwater discharge.

Finally, the orographic effect of ice sheet retreat induces little change in the tropical North African monsoon precipitation and a dipole anomalous pattern of the Asian monsoon precipitation, leading to a nearly unchanged overall AAMP (Figs. $2 \mathrm{i}$ and $6 \mathrm{~d}$ ). Therefore, the combined effects of changes in orography and meltwater discharge related to retreating ice sheets are unfavorable for precipitation in North China and tropical North Africa, and they cancel each other out in India and southwestern China. In summary, our study indicates that the increase in orbital insolation and GHGs may result in an enhanced AAMP but the retreat of ice sheet by the consequent warming may offset the enhancement in monsoonal precipitation over North China and tropical North Africa.

The TraCE-21ka performs well in reproducing the reconstructed AAMP since the LGM, but the uncertainties should be considered. First, although most of the AAMP proxies show an increasing trend from early to middle Holocene and decreasing in the late Holocene, there is a debate about the timing of maximum AAMP or humid condition during the Holocene [i.e., the Holocene Optimum (HO)]. Taking the East Asian monsoon records for example, An et al. (2000) pointed that the HO occurred earliest in North China around $10 \mathrm{ka}$ BP. However, later studies found that South China's stalagmite records indicate the $\mathrm{HO}$ around 10 ka BP, whereas North China's lake records exhibit the HO around 6 ka BP (Yuan et al. 2004; Chen et al. 2008; Zhou et al. 2016; Li et al. 2018). Second, the TraCE-full results show that a maximum EASM occurs around $10 \mathrm{ka}$ BP in North China, in agreement with An et al. (2000), but it may be related to the model's unrealistic performance. The spatial resolution of TraCE-21ka simulation is too coarse to match the reconstructions accurately. Besides, the TraCE-21ka is found to simulate a farther-north ITCZ than observations (Shanahan et al. 2015). Therefore, uncertainties exist in both proxies and model simulations. We only discuss the dominant mode here, but the remainder of EOF modes also include important spatiotemporal variability of the AAMP (Liu et al. 2014a). Although the sensitivity experiments isolate the role of different external forcings, the nonlinear effect of individual forcings (i.e., the influence of ice sheets on modulating the orbital-monsoon relationship) is hard to investigate.

Nevertheless, we presented a detailed discussion on the AAMP variations in response to various forcings, such as varying insolation, GHGs, and ice sheet retreat. It further provides a reference for a future warmer world with potential melting of the Greenland Ice Sheet, but further research is necessary to test the sensitivity of the AAMP to ice sheet retreat in different regions. The conclusions are meaningful to a thorough understanding of longer-timescale AAMP changes and future projections. 
Acknowledgments. We thank the TraCE-21ka group for sharing their model output via the Earth System Grid of the National Center for Atmospheric Research. The model data are available online (https://www.earthsystemgrid.org/ project/trace.html). This study is supported by the National Key Research and Development Program of China (Grant 2016YFA0600703), the Strategic Priority Research Program of Chinese Academy of Sciences (XDA20070103), the Startup Foundation for Introducing Talent of NUIST (Grant 2017r105), and the Priority Academic Program Development (PAPD) of Jiangsu Higher Education Institution.

\section{REFERENCES}

An, Z. S., S. C. Porter, J. E. Kutzbach, X. Wu, S. Wang, X. Liu, X. Li, and W. Zhou, 2000: Asynchronous Holocene optimum of the East Asian monsoon. Quat. Sci. Rev., 19, 743-762, https:// doi.org/10.1016/S0277-3791(99)00031-1.

Anchukaitis, K. J., B. M. Buckley, E. R. Cook, B. I. Cook, R. D. D'Arrigo, and C. M. Ammann, 2010: Influence of volcanic eruptions on the climate of the Asian monsoon region. Geophys. Res. Lett., 37, L22703, https://doi.org/10.1029/2010GL044843.

Armitage, S. J., C. S. Bristow, and N. A. Drake, 2015: West African monsoon dynamics inferred from abrupt fluctuations of Lake Mega-Chad. Proc. Natl. Acad. Sci. USA, 112, 8543-8548, https://doi.org/10.1073/pnas.1417655112.

Ashfaq, M., Y. Shi, W. W. Tung, R. J. Trapp, X. J. Gao, J. S. Pal, and N. S. Diffenbaugh, 2009: Suppression of South Asian summer monsoon precipitation in the 21st century. Geophys. Res. Lett., 36, L01704, https://doi.org/10.1029/2008GL036500.

Ba, J., and Coauthors, 2014: A multi-model comparison of Atlantic multidecadal variability. Climate Dyn., 43, 2333-2348, https:// doi.org/10.1007/s00382-014-2056-1.

Berger, A. L., 1978: Long-term variations of daily insolation and Quaternary climatic changes. J. Atmos. Sci., 35, 2362-2367, https:// doi.org/10.1175/1520-0469(1978)035<2362:LTVODI >2.0.CO;2.

Bollasina, M. A., Y. Ming, and V. Ramaswamy, 2011: Anthropogenic aerosols and the weakening of the South Asian summer monsoon. Science, 334, 502-505, https://doi.org/10.1126/ science.1204994.

Byrne, M. P., A. G. Pendergrass, A. D. Rapp, and K. R. Wodzicki, 2018: Response of the intertropical convergence zone to climate change: Location, width, and strength. Curr. Climate Change Rep., 4, 355-370, https://doi.org/10.1007/s40641-0180110-5.

Cai, Y. J., and Coauthors, 2015: Variability of stalagmite-inferred Indian monsoon precipitation over the past 252,000 y. Proc. Natl. Acad. Sci. USA, 112, 2954-2959, https://doi.org/10.1073/ pnas.1424035112.

Caley, T., and Coauthors, 2011: Orbital timing of the Indian, East Asian and African boreal monsoons and the concept of a 'global monsoon.' Quat. Sci. Rev., 30, 3705-3715, https:// doi.org/10.1016/j.quascirev.2011.09.015.

Carlson, A. E., D. W. Oppo, R. E. Came, A. N. LeGrande, L. D. Keigwin, and W. B. Curry, 2008: Subtropical Atlantic salinity variability and Atlantic meridional circulation during the last deglaciation. Geology, 36, 991-994, https://doi.org/10.1130/ G25080A.1.
Chen, F. H., and Coauthors, 2008: Holocene moisture evolution in arid central Asia and its out-of-phase relationship with Asian monsoon history. Quat. Sci. Rev., 27, 351-364, https://doi.org/ 10.1016/j.quascirev.2007.10.017.

Chen, T. C., 2003: Maintenance of summer monsoon circulations: A planetary-scale perspective. J. Climate, 16, 2022-2037, https://doi.org/10.1175/1520-0442(2003)016<2022: MOSMCA $>2.0 . \mathrm{CO} ; 2$.

Chou, C., J. C. Chiang, C. W. Lan, C. H. Chung, Y. C. Liao, and C. J. Lee, 2013: Increase in the range between wet and dry season precipitation. Nat. Geosci., 6, 263-267, https://doi.org/ 10.1038/ngeo1744.

Clark, P. U., and Coauthors, 2009: The Last Glacial Maximum. Science, 325, 710-714, https://doi.org/10.1126/science.1172873.

Dallmeyer, A., and Coauthors, 2015: The evolution of submonsoon systems in the Afro-Asian monsoon region during the Holocene comparison of different transient climate model simulations. Climate Past, 11, 305-326, https://doi.org/10.5194/ cp-11-305-2015.

Dykoski, C. A., and Coauthors, 2005: A high-resolution, absolutedated Holocene and deglacial Asian monsoon record from Dongge Cave, China. Earth Planet. Sci. Lett., 233, 71-86, https://doi.org/10.1016/j.epsl.2005.01.036.

Fleitmann, D., and Coauthors, 2007: Holocene ITCZ and Indian monsoon dynamics recorded in stalagmites from Oman and Yemen (Socotra). Quat. Sci. Rev., 26, 170-188, https://doi.org/ 10.1016/j.quascirev.2006.04.012.

Gasse, F., 2000: Hydrological changes in the African tropics since the Last Glacial Maximum. Quat. Sci. Rev., 19, 189-211, https://doi.org/10.1016/S0277-3791(99)00061-X.

_ , and E. Van Campo, 1994: Abrupt post-glacial climate events in West Asia and North Africa monsoon domains. Earth Planet. Sci. Lett., 126, 435-456, https://doi.org/10.1016/0012821X(94)90123-6.

Gebregiorgis, D., E. C. Hathorne, A. V. Sijinkumar, B. N. Nath, D. Nurnberg, and M. Frank, 2016: South Asian summer monsoon variability during the last similar to 54 kyrs inferred from surface water salinity and river runoff proxies. Quat. Sci. Rev., 138, 6-15, https://doi.org/10.1016/j.quascirev.2016.02.012.

Goswami, B. N., V. Krishnamurthy, and H. Annamalai, 1999: A broad scale circulation index for the interannual variability of the Indian summer monsoon. Quart. J. Roy. Meteor. Soc., 125, 611-633, https://doi.org/10.1002/qj.49712555412.

Govil, P., and P. D. Naidu, 2011: Variations of Indian monsoon precipitation during the last $32 \mathrm{kyr}$ reflected in the surface hydrography of the Western Bay of Bengal. Quat. Sci. Rev., 30, 3871-3879, https://doi.org/10.1016/j.quascirev. 2011.10.004.

Greve, R., 2000: On the response of the Greenland ice sheet to greenhouse climate change. Climatic Change, 46, 289-303, https://doi.org/10.1023/A:1005647226590.

He, F., 2011: Simulating transient climate evolution of the last deglaciation with CCSM3. Ph.D. thesis, University of WisconsinMadison, 171 pp., http://www.cgd.ucar.edu/ccr/TraCE/doc/ He_PhD_dissertation_UW_2011.pdf.

Huybrechts, P., H. Goelzer, I. Janssens, E. Driesschaert, T. Fichefet, H. Goosse, and M. F. Loutre, 2011: Response of the Greenland and Antarctic Ice Sheets to multi-millennial greenhouse warming in the Earth system model of intermediate complexity LOVECLIM. Surv. Geophys., 32, 397416, https://doi.org/10.1007/s10712-011-9131-5.

IPCC, 2013: Climate Change 2013: The Physical Science Basis. T. F. Stocker et al., Eds., Cambridge University Press, 1535 pp. 
Jiang, D. B., Z. P. Tian, and X. M. Lang, 2015a: Mid-Holocene global monsoon area and precipitation from PMIP simulations. Climate Dyn., 44, 2493-2512, https://doi.org/10.1007/ s00382-014-2175-8.

M. Kageyama, and G. Ramstein, 2015b: The concept of global monsoon applied to the last glacial maximum: A multi-model analysis. Quat. Sci. Rev., 126, 126-139, https:// doi.org/10.1016/j.quascirev.2015.08.033.

Joos, F., and R. Spahni, 2008: Rates of change in natural and anthropogenic radiative forcing over the past 20,000 years. Proc. Natl. Acad. Sci. USA, 105, 1425-1430, https://doi.org/10.1073/ pnas.0707386105.

Kudrass, H. R., A. Hofmann, H. Doose, K. Emeis, and H. Erlenkeuser, 2001: Modulation and amplification of climatic changes in the Northern Hemisphere by the Indian summer monsoon during the past $80 \mathrm{ky}$. Geology, 29, 63-66, https://doi.org/10.1130/00917613(2001)029<0063:MAAOCC $>2.0 . C O ; 2$.

Lau, K. M., M. K. Kim, and K. M. Kim, 2006: Asian summer monsoon anomalies induced by aerosol direct forcing: The role of the Tibetan Plateau. Climate Dyn., 26, 855-864, https:// doi.org/10.1007/s00382-006-0114-z.

Lee, J. Y., and B. Wang, 2014: Future change of global monsoon in the CMIP5. Climate Dyn., 42,101-119, https://doi.org/10.1007/ s00382-012-1564-0.

Li, J., and Coauthors, 2018: Regional-scale precipitation anomalies in northern China during the Holocene and possible impact on prehistoric demographic changes. Geophys. Res. Lett., 45, 12 477-12 486, https://doi.org/10.1029/2018GL078873.

Lin, Z. D., and R. Y. Lu, 2005: Interannual meridional displacement of the East Asian upper-tropospheric jet stream in summer. $A d v$. Atmos. Sci., 22, 199-211, https://doi.org/10.1007/BF02918509.

Liu, Z. Y., and Coauthors, 2009: Transient simulation of last deglaciation with a new mechanism for Bølling-Allerød warming. Science, 325, 310-314, https://doi.org/10.1126/science.1171041.

-, and Coauthors, 2014a: Chinese cave records and the East Asia summer monsoon. Quat. Sci. Rev., 83, 115-128, https:// doi.org/10.1016/j.quascirev.2013.10.021.

— Z. Y. Lu, X. Y. Wen, B. L. Otto-Bliesner, A. Timmermann, and K. M. Cobb, 2014b: Evolution and forcing mechanisms of El Niño over the past 21,000 years. Nature, 515, 550-553, https://doi.org/10.1038/nature13963.

Lu, F. Z., and Coauthors, 2019: Variability of East Asian summer monsoon precipitation during the Holocene and possible forcing mechanisms. Climate Dyn., 52, 969-989, https:// doi.org/10.1007/s00382-018-4175-6.

Lu, H. Y., and Coauthors, 2013: Variation of East Asian monsoon precipitation during the past $21 \mathrm{k} . \mathrm{y}$. and potential $\mathrm{CO}_{2}$ forcing. Geology, 41, 1023-1026, https://doi.org/10.1130/G34488.1.

Man, W. M., T. J. Zhou, and J. H. Jungclaus, 2014: Effects of large volcanic eruptions on global summer climate and East Asian monsoon changes during the last millenium: Analysis of MPIESM simulations. J. Climate, 27, 7394-7409, https://doi.org/ 10.1175/JCLI-D-13-00739.1.

Pausata, F. S. R., D. S. Battisti, K. H. Nisancioglu, and C. M. Bitz, 2011: Chinese stalagmite $\delta^{18} \mathrm{O}$ controlled by changes in the Indian monsoon during a simulated Heinrich event. Nat. Geosci., 4, 474-480, https://doi.org/10.1038/ngeo1169.

Peltier, W. R., 2004: Global glacial isostasy and the surface of the ice-age Earth: The ICE-5G (VM2) model and GRACE. Annu. Rev. Earth Planet. Sci., 32, 111-149, https://doi.org/ 10.1146/annurev.earth.32.082503.144359.

Pinot, S., G. Ramstein, S. P. Harrison, I. C. Prentice, J. Guiot, M. Stute, and S. Joussaume, 1999: Tropical paleoclimates at the Last Glacial Maximum: Comparison of Paleoclimate Modeling Intercomparison Project (PMIP) simulations and paleodata. Climate Dyn., 15, 857-874, https://doi.org/10.1007/ s003820050318.

Qi, L., J. H. He, Z. Q. Zhang, and J. N. Song, 2008: Seasonal cycle of the zonal land-sea thermal contrast and East Asian subtropical monsoon circulation. Chin. Sci. Bull., 53, 131-136, https://doi.org/10.1007/s11434-007-0518-0.

Ramstein, G., M. Kageyama, J. Guiot, H. Wu, C. Hély, G. Krinner, and S. Brewer, 2007: How cold was Europe at the Last Glacial Maximum? A synthesis of the progress achieved since the first PMIP model-data comparison. Climate Past, 3, 331-339, https://doi.org/10.5194/cp-3-331-2007.

Revel, M., and Coauthors, 2014: 21,000 Years of Ethiopian African monsoon variability recorded in sediments of the western Nile deep-sea fan. Reg. Environ. Change, 14, 1685-1696, https:// doi.org/10.1007/s10113-014-0588-x.

Schneider, T., T. Bischoff, and G. H. Haug, 2014: Migrations and dynamics of the intertropical convergence zone. Nature, $\mathbf{5 1 3}$, 45-53, https://doi.org/10.1038/nature13636.

Shanahan, T. M., and Coauthors, 2015: The time-transgressive termination of the African Humid Period. Nat. Geosci., 8, 140 144, https://doi.org/10.1038/ngeo2329.

Tan, L. C., Y. J. Cai, H. Cheng, Z. S. An, and R. L. Edwards, 2009: Summer monsoon precipitation variations in central China over the past 750 years derived from a high-resolution absolutedated stalagmite. Palaeogeogr. Palaeoclimatol. Palaeoecol., 280 432-439, https://doi.org/10.1016/j.palaeo.2009.06.030.

Tierney, J. E., F. S. R. Pausata, and P. deMenocal, 2016: Deglacial Indian monsoon failure and North Atlantic stadials linked by Indian Ocean surface cooling. Nat. Geosci., 9, 46-50, https:// doi.org/10.1038/ngeo2603.

Trenberth, K. E., D. P. Stepaniak, and J. M. Caron, 2000: The global monsoon as seen through the divergent atmospheric circulation. J. Climate, 13, 3969-3993, https://doi.org/10.1175/ 1520-0442(2000)013<3969:TGMAST>2.0.CO;2.

Wang, B., and Z. Fan, 1999: Choice of South Asian summer monsoon indices. Bull. Amer. Meteor. Soc., 80, 629-638, https://doi.org/ 10.1175/1520-0477(1999)080<0629:COSASM > 2.0.CO;2.

- J. Liu, H. J. Kim, P. J. Webster, and S. Y. Yim, 2012: Recent change of the global monsoon precipitation (1979-2008). Climate Dyn., 39, 1123-1135, https://doi.org/10.1007/s00382011-1266-z.

, and B. Q. Xiang, 2013: Northern Hemisphere summer monsoon intensified by mega-El Niño/ southern oscillation and Atlantic multidecadal oscillation. Proc. Natl. Acad. Sci. USA, 110, 5347-5352, https://doi.org/ 10.1073/pnas.1219405110.

, and Coauthors, 2018: Toward predicting changes in the land monsoon rainfall a decade in advance. J. Climate, 31, 26992714, https://doi.org/10.1175/JCLI-D-17-0521.1.

Wang, N., D. B. Jiang, and X. M. Lang, 2018: Northern westerlies during the Last Glacial Maximum: Results from CMIP5 simulations. J. Climate, 31, 1135-1153, https://doi.org/10.1175/ JCLI-D-17-0314.1.

Wang, Y. B., X. Q. Liu, and U. Herzschuh, 2010: Asynchronous evolution of the Indian and East Asian summer monsoon indicated by Holocene moisture patterns in monsoonal central Asia. Earth-Sci. Rev., 103, 135-153, https://doi.org/10.1016/ j.earscirev.2010.09.004.

Wang, Y. J., H. Cheng, R. L. Edwards, Z. S. An, J. Y. Wu, C.-C. Shen, and J. A. Dorale, 2001: A high-resolution absolute-dated 
late Pleistocene monsoon record from Hulu Cave, China. Science, 294, 2345-2348, https://doi.org/10.1126/science.1064618.

_- and Coauthors, 2008: Millennial- and orbital-scale changes in the East Asian monsoon over the past 224,000 years. Nature, 451, 1090-1093, https://doi.org/10.1038/nature06692.

Weber, S. L., and Coauthors, 2007: The modern and glacial overturning circulation in the Atlantic Ocean in PMIP coupled model simulations. Climate Past, 3, 51-64, https://doi.org/ 10.5194/cp-3-51-2007.

Webster, P. J., and S. Yang, 1992: Monsoon and ENSO: Selectively interactive systems. Quart. J. Roy. Meteor. Soc., 118, 877-926, https://doi.org/10.1002/qj.49711850705.

Weldeab, S., D. W. Lea, R. R. Schneider, and N. Andersen, 2007: 155,000 years of West African monsoon and ocean thermal evolution. Science, 316, 1303-1307, https://doi.org/10.1126/ science. 1140461.

Wen, X. Y., Z. Y. Liu, S. W. Wang, J. Cheng, and J. Zhu, 2016: Correlation and anti-correlation of the East Asian summer and winter monsoons during the last 21,000 years. Nat. Commun., 7, 11999, https://doi.org/10.1038/NCOMMS11999.

Yan, M., B. Wang, and J. Liu, 2016: Global monsoon change during the Last Glacial Maximum: A multi-model study. Climate Dyn., 47, 359-374, https://doi.org/10.1007/s00382-015-2841-5.

Yan, Q., and Z. S. Zhang, 2017: Dominating roles of ice sheets and insolation in variation of tropical cyclone genesis potential over the North Atlantic during the last 21,000 years. Geophys. Res. Lett., 44, 10 624-10 632, https://doi.org/10.1002/ 2017 GL075786.

_ - - H. J. Wang, and R. Zhang, 2014: Simulation of Greenland ice sheet during the mid-Pliocene. Chin. Sci. Bull., 59, 201-211, https://doi.org/10.1007/s11434-013-0001-z.
Yang, S. L., Z. L. Ding, Y. Y. Li, X. Wang, W. Y. Jiang, and X. F. Huang, 2015: Warming-induced northwestward migration of the East Asian monsoon rain belt from the Last Glacial Maximum to the mid-Holocene. Proc. Natl. Acad. Sci. USA, 112, 1317813183, https://doi.org/10.1073/pnas.1504688112.

Yim, S.-Y., B. Wang, J. Liu, and Z. Wu, 2014: A comparison of regional monsoon variability using monsoon indices. Climate Dyn., 43, 1423-1437, https://doi.org/10.1007/s00382-013-1956-9.

Yu, R. C., B. Wang, and T. J. Zhou, 2004: Tropospheric cooling and summer monsoon weakening trend over East Asia. Geophys. Res. Lett., 31, L22212, https://doi.org/10.1029/2004GL021270.

Yuan, D. X., and Coauthors, 2004: Timing, duration, and transitions of the last interglacial Asian monsoon. Science, 304, 575578, https://doi.org/10.1126/science.1091220.

Zhang, X. J., and L. Y. Jin, 2016: Association of the Northern Hemisphere circumglobal teleconnection with the Asian summer monsoon during the Holocene in a transient simulation. Holocene, 26, 290-301, https://doi.org/10.1177/0959683615608689.

Zhou, T. J., L. X. Zhang, and H. M. Li, 2008: Changes in global land monsoon area and total rainfall accumulation over the last half century. Geophys. Res. Lett., 35, L16707, https://doi.org/ 10.1029/2008GL034881.

Zhou, X., and Coauthors, 2016: Time-transgressive onset of the Holocene Optimum in the East Asian monsoon region. Earth Planet. Sci. Lett., 456, 39-46, https://doi.org/10.1016/ j.epsl.2016.09.052.

Zhu, J., Z. Y. Liu, X. Zhang, I. Eisenman, and W. Liu, 2014: Linear weakening of the AMOC in response to receding glacial ice sheets in CCSM3. Geophys. Res. Lett., 41, 6252-6258, https:// doi.org/10.1002/2014GL060891. 